\title{
Durability Performance of Concrete using Rice Husk Ash
}

\author{
Jeong, Euy-Chang Shin, Sang-Yeop Kim, Young-Soo* \\ Department of Architectural Engineering, Pusan National University, GeumJeong-Gu, Pusan, 609-735, Korea
}

\begin{abstract}
The purpose of this study was to investigate the durability performance of concrete that includes rice husk ash. Chloride diffusion coefficient obtained through a rapid chloride penetration test and depth of $\mathrm{CO}_{2}$ penetration obtained through a rapid carbonation test were used to evaluate latent durability. Durability characteristics for rice husk ash replacement and age were determined. Through the experiment, it was found that when the replacement ratio of rice husk ash was increased from $0 \%$ to $10 \%$, the compressive strength of concrete containing rice husk ash was similar to that of concrete containing silica fume. This shows that the durability performance of concrete containing rice husk is excellent compared to other concretes containing admixtures.
\end{abstract}

Keywords : rice husk ash, durability performance, chloride penetration test, rapid carbonation test

\section{Introduction}

\subsection{Research objective}

Perceived as a semi-permanent material with good durability, rebar concrete is in wide use for civil engineering and construction structures. But if chloride penetration and neutralization cause chloride and $\mathrm{CO}_{2}$ to penetrate into concrete, they facilitate rebar rust, and early deterioration or cracks can develop as a consequence[1,2].

To prevent the damages that can be caused by the penetration of rebar rust ions from outside, the internal structure of concrete should be tightened. The application of an admixture is the most widely used method of controlling the ions to improve the internal structure of concrete and keep chloride from moving or penetrating[3]. Of

Received : September 10, 2012

Revision received : January 22, 2013

Accepted : January 24, 2013

* Corresponding author : Kim, Young-Soo

[Tel: +82-51-510-2443 , E-mail: kys@pusan.ac.kr]

(c)2013 The Korea Institute of Building Construction, All rights reserved. the mineral admixtures, the blast furnace slag(BFS) that is generally used has a relatively low initial strength compared with $\mathrm{OPC}$, fly ash(FA) does not provide a constant quality level, and silica fume(SF) has good performance but is expensive and is not produced in Korea[4].

For this reasons, rice husk ash(RHA) is being considered as a substitute for the existing admixtures, as it has similar chemical properties and shows pozzolanic reaction.

More than 1.5 million tons of RHA is available because it is generated as an agricultural byproduct, and it can be recycled in a large quantity as a construction material $[5,6]$.

In addition, considering its chemical properties, $\mathrm{SiO}_{2}$ accounts for more than $90 \%$, and the particle size is small, controlling and slowing the movement of ions. The performance of RHA is similar to that of silica fume[7,8,9].

Likewise, RHA is currently being studied as a substitute for SF due to its filling effect and pozzolanic reaction. When added to concrete, it is believed that it will improve the resistance to 
rebar of concrete structures by suppressing the penetration of chloride ions and $\mathrm{CO}_{2}$ from outside.

From this perspective, this study aims to understand durability performance according the amount of RHA by performing a comparative analysis of the compressive strength of RHA-mixed concrete and existing admixture-mixed concrete, referring to the coefficient of chloride diffusion and facilitated neutralization tests.

\subsection{Research method and scope}

For this study, rice husk was incinerated at $600^{\circ} \mathrm{C}$ for four hours and then the concrete was manufactured according to mix proportion, and was compared with concretes that used conventional admixtures.

To evaluate the basic physical properties of the concrete with rice husk ash, the compressive strength of each specimen was measured, and to observe the chloride penetration and resistance performance against neutralization, facilitated neutralization test and chloride penetration test were conducted based on NT-Build 492. Based on the tests, chloride penetration coefficient and neutralization depth were measured, and then a comparative analysis was performed to assess the durability performance of the concrete with rice husk ash.

\section{Experiment plan}

\subsection{Test materials}

\subsubsection{Cement}

The cement used in this study is Ordinary Portland Cement(OPC) produced in Korea, and its physical properties are indicated in Table 1.
Table 1. Chemical and Physical properties of cement

\begin{tabular}{|c|c|c|c|c|c|}
\hline \multicolumn{2}{|c|}{ Type } & \multicolumn{4}{|c|}{ Type I Portland Cement } \\
\hline \multicolumn{2}{|c|}{ Fineness $\left(\mathrm{cm}^{2} / \mathrm{g}\right)$} & \multicolumn{4}{|c|}{3,266} \\
\hline \multicolumn{2}{|c|}{ Density $\left(\mathrm{cm}^{2} / \mathrm{g}\right)$} & \multicolumn{4}{|c|}{3.15} \\
\hline \multirow{7}{*}{$\begin{array}{l}\text { Chemical } \\
\text { composition } \\
(\%)\end{array}$} & $\mathrm{SiO}_{2}$ & 20.71 & \multirow{7}{*}{$\begin{array}{l}\text { Compound } \\
\text { composition } \\
(\%)\end{array}$} & \multirow[t]{2}{*}{$\mathrm{C}_{3} \mathrm{~S}$} & \multirow[t]{2}{*}{48.20} \\
\hline & $\mathrm{Al}_{2} \mathrm{O}_{3}$ & 5.56 & & & \\
\hline & $\mathrm{Fe}_{2} \mathrm{O}_{3}$ & 3.03 & & $\mathrm{C}_{2} \mathrm{~S}$ & 23.00 \\
\hline & $\mathrm{CaO}$ & 62.25 & & \multirow[b]{2}{*}{$\mathrm{C}_{3} \mathrm{~A}$} & \multirow[b]{2}{*}{9.60} \\
\hline & $\mathrm{MgO}$ & 3.40 & & & \\
\hline & $\mathrm{SO}_{3}$ & 2.50 & & \multirow[b]{2}{*}{$\mathrm{C}_{4} \mathrm{AF}$} & \multirow[b]{2}{*}{9.20} \\
\hline & L.O.I & 1.42 & & & \\
\hline
\end{tabular}

\subsubsection{Aggregate}

Crushed stone less than $19 \mathrm{~mm}$ in diameter was used as coarse aggregate, and river sand less than $5 \mathrm{~mm}$ in diameter was used as fine aggregate. The grain sizes of coarse and fine aggregate were adjusted to be within standard grain size distribution. The physical properties of the aggregate are indicated in Table 2.

Table 2. Chemical and physical composition of aggregate

\begin{tabular}{ccc}
\hline Type & $\begin{array}{c}\text { Coarse } \\
\text { Aggregate }\end{array}$ & $\begin{array}{c}\text { Fine } \\
\text { Aggregate }\end{array}$ \\
\hline $\begin{array}{c}\text { Maximum size of } \\
\text { aggregate }(\mathrm{mm})\end{array}$ & 19 & 5 \\
Fineness Modulus & 6.8 & 2.85 \\
$\begin{array}{c}\text { Specific Gravity } \\
\left(\mathrm{g} / \mathrm{cm}^{3}\right)\end{array}$ & 2.57 & 2.57 \\
$\begin{array}{c}\text { Absorption }(\%) \\
\text { Bulk Density of } \\
\text { Aggregate }\left(\mathrm{kg} / \mathrm{m}^{3}\right)\end{array}$ & 1.32 & 2.33 \\
\hline
\end{tabular}

\subsubsection{Admixture materials}

Three types of BFS and two types of FA were used as admixture in the research. In addition, condensed SF manufactured in Norway was also used. 
Table 3. Chemical properties of mineral admixture

\begin{tabular}{cccc}
\hline Composition (\%) & $\begin{array}{c}\text { Ground } \\
\text { Granulated Blast } \\
\text { Furnace Slag }\end{array}$ & Fly Ash & $\begin{array}{c}\text { Silica } \\
\text { Fume }\end{array}$ \\
\hline $\mathrm{SiO}_{2}$ & 34.29 & 61.20 & 92.01 \\
$\mathrm{CaO}$ & 42.41 & 1.82 & 0.60 \\
$\mathrm{Al}_{2} \mathrm{O}_{3}$ & 13.19 & 24.92 & 2.00 \\
$\mathrm{Fe}_{2} \mathrm{O}_{3}$ & 0.59 & 4.63 & 2.00 \\
$\mathrm{MgO}_{\mathrm{SO}}$ & 4.11 & 0.62 & 0.60 \\
$\mathrm{~K}_{2} \mathrm{O}$ & 3.17 & - & - \\
\hline
\end{tabular}

\subsubsection{Rice Husk Ash(RHA)}

RHA was crushed using Ball Mill after incineration of the rice husk produced in $\mathrm{K}$ region in an electric furnace at $600^{\circ} \mathrm{C}$, and its physical properties are indicated in Table 4.

Table 4. Chemical and physical properties of rice husk

\begin{tabular}{ccc}
\hline \multicolumn{2}{c}{ Fineness $\left(\mathrm{m}^{2} / \mathrm{g}\right)$} & 30,000 \\
\hline \multicolumn{2}{c}{ Density $\left(\mathrm{cm}_{2} / \mathrm{g}\right)$} & 2.10 \\
& $\mathrm{SiO}_{2}$ & 89,18 \\
& $\mathrm{Al}_{2} \mathrm{O}_{3}$ & 0.113 \\
Chemical & $\mathrm{Fe}_{2} \mathrm{O}_{3}$ & 0.076 \\
composition & $\mathrm{CaO}$ & 0.278 \\
$(\%)$ & $\mathrm{MgO}$ & 0.253 \\
& $\mathrm{Na}_{2} \mathrm{O}_{3}$ & 0.884 \\
& L.O.I & 7.98 \\
\hline
\end{tabular}

\subsection{Test specimens}

\subsubsection{Test factors and level}

To review the impact of RHA-mixed concrete on the resistance to rebar rust, the mixing proportion of RHA was set as the main test factor.

As the test factors, the mix design was set to meet target slump of $120 \pm 25 \mathrm{~mm}$ and air content of $4.5 \pm 1.5 \%$. In addition, the mix proportion of RHA was set at 5, 10, 15, and 20\%, and it was mixed to concrete. To perform a comparative analysis of the compressive strength of the RHA-mixed concrete and the existing admixture-mixed concrete, specimens were manufactured with mix proportion of FA was set at 10 and 20\%, of BFS was set at 10, 20, and $30 \%$, and of SF was set at 5 and $10 \%$ based on the literature review. Table 5 is the mix design used in the experiment, and the evaluation items are shown in Table 6 .

To mix concrete, coarse and fine aggregate were input and dry mixed for 30 seconds, and then cement and water were added and mixed for three

Table 5. Mixing design of Concrete

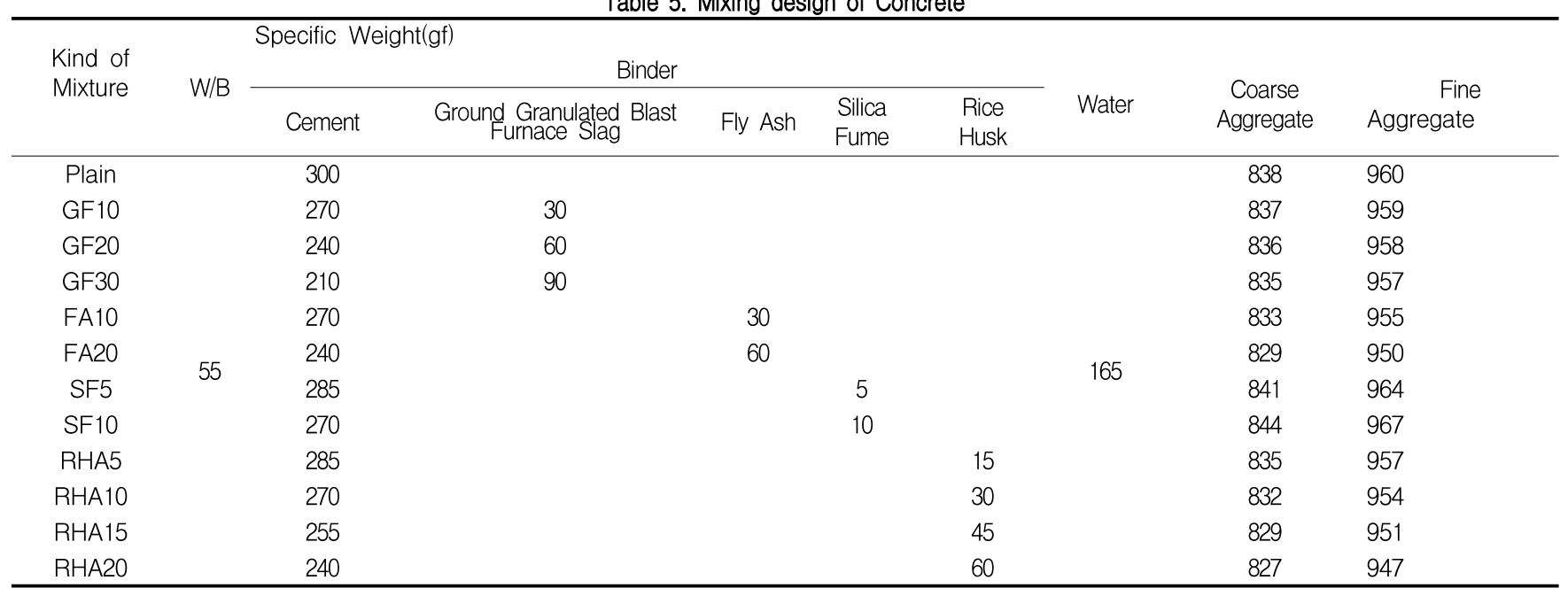

Ex) Plain(GF, FA, SF, RHA)OO ※ W/B : Water Binder Ratio

Plain : Portland Cement, GF : Ground Granulated Blast Furnace Slag, FA : Fly Ash SF : Silica Fume, RHA : Rice Husk Ash 
minutes (mixing for 1 minute $\rightarrow$ pausing for 1 minute $\rightarrow$ mixing another 2 minutes)

To measure compressive strength, 12 specimens for each batch were manufactured in a cylindrical form with dimensions of $\varnothing 100 \times 200 \mathrm{~mm}$, and to measure neutralization depth, 6 specimens for each batch were manufactured in a cylindrical form with dimensions of $\varnothing 100 \times 200 \mathrm{~mm}$. In addition, to evaluate chloride penetration depth, 12 specimens for each batch were manufactured in a cylindrical form with $\varnothing 100 \times 200 \mathrm{~mm}$ in dimension.

All the specimens were cured for 24 hours in wet conditions after placement, and then water cured in a water chamber where the temperature was maintained at $20 \pm 3^{\circ} \mathrm{C}$ after being removed from the mold.

Table 6. Experiment factor and assessment

\begin{tabular}{|c|c|c|}
\hline \multirow{6}{*}{$\begin{array}{l}\text { Experiment } \\
\text { Factor } \\
\text { and } \\
\text { Standard }\end{array}$} & W/B Ratio(\%) & 0.55 \\
\hline & Slump $(m m)$ & $120 \pm 25$ \\
\hline & Air Contents(\%) & $4.5 \pm 1.5$ \\
\hline & $\begin{array}{c}\text { Ground Granulated Blast } \\
\text { Furnace Slag(\%) }\end{array}$ & $10,20,30$ \\
\hline & Fly Ash (\%) & 10,20 \\
\hline & Silica Fume $(\%)$ & 5,10 \\
\hline \multirow{3}{*}{ Assessment } & $\begin{array}{l}\text { Compressive Strength } \\
\text { (Day) }\end{array}$ & $3,7,14,28$ \\
\hline & $\begin{array}{c}\text { Chloride Ion Migration } \\
\text { Coefficient of Concrete } \\
\text { (Day) }\end{array}$ & 28,56 \\
\hline & $\begin{array}{l}\text { Observation of } \\
\text { Depth of Carbonation } \\
\text { (Week) }\end{array}$ & $\begin{array}{c}\text { After } 28 \text { Day } \\
\text { Curing, } \\
1,2,4,8\end{array}$ \\
\hline
\end{tabular}

\subsection{Test methodology}

\subsubsection{Compressive strength}

To understand physical properties, compressive strength was measured based on KS F 2405 "Method of Test for Compressive Strength." Specimens were removed from the water chamber after a certain period of curing time, the surface was abraded within $2 \mathrm{~mm}$ using a grinding capping machine, and the compressive strength was measured using a 200-ton Universal Testing Machine.

\subsubsection{Facilitated neutralization test}

The neutralization depth was measured based on KS F 2584 "Standard test method for accelerated carbonation of concrete." The specimens cured for 28 days were cured again in the facilitated neutralization test machine (temperature: $20^{\circ} \mathrm{C}$, relative humidity: 60\%, $\mathrm{CO}_{2}$ concentration: $5.0 \%$ ) for 4 or 8 weeks, and then the specimens were split, phenolphthalein in $1 \%$ alcoholic solution was used as a visual indicator, and the carbonation depth was measured at 3 locations in each specimen using a micrometer.

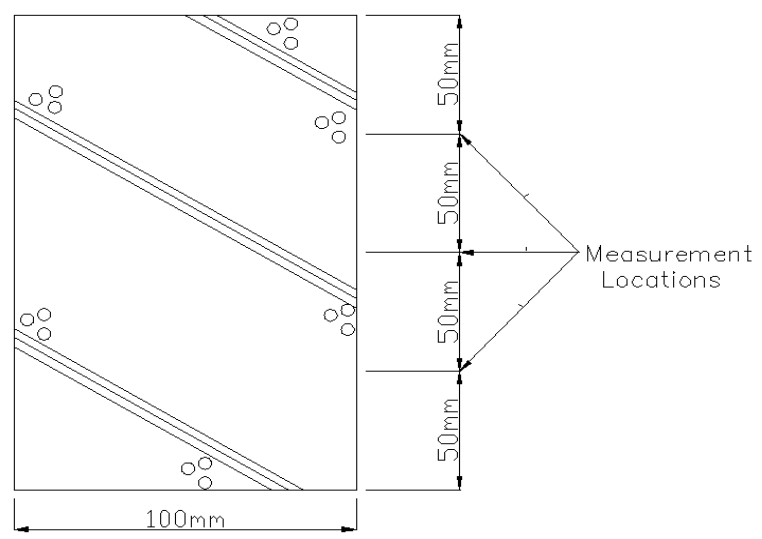

Figure 1. Measurement Locations of Carbonation Depth

\subsubsection{Chloride diffusion coefficient}

The chloride diffusion coefficient test was implemented based on the previous studies to carry out a comparison between materials[10]. The concrete specimens were water cured for 28 or 56 days, and then cut to $50 \mathrm{~mm}$ in thickness using a cutter. The chloride diffusion test was performed in compliance with the European Test Directives. As illustrated in Figure 3, DC 30V was supplied for 24 hours by setting $0.3 \mathrm{~N} \mathrm{NaOH}$ as anode and $10 \%$ $\mathrm{NaCl}$ solution as cathode to the specimens. Then, $0.1 \mathrm{~N}$ silver nitrate was sprayed on the split 
specimen to measure the depth, as shown in Figure

3. The figures obtained through the depth test were substituted in Exp.1 for calculation. Through the process, a comparative analysis of the resistance to chloride of each specimen was conducted.

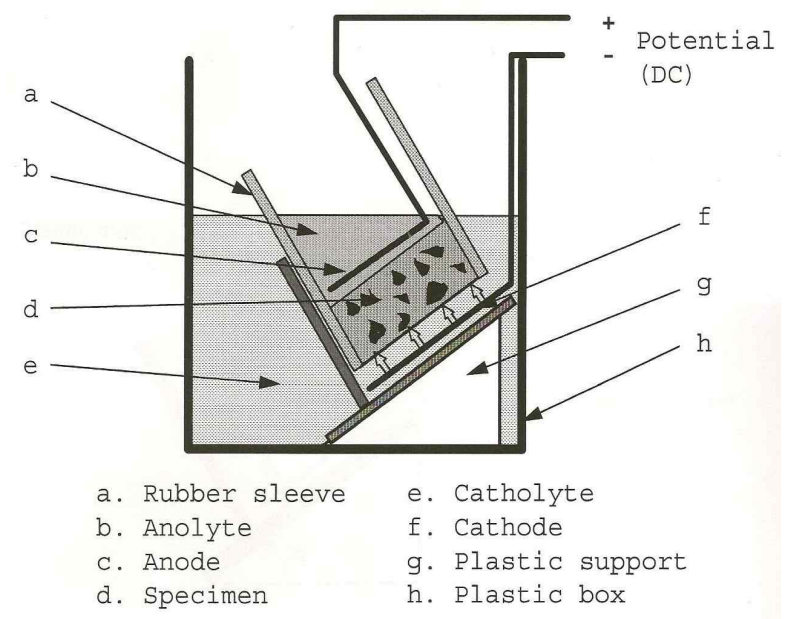

Figure 2. Chloride Ion Migration Accelerated Test Device

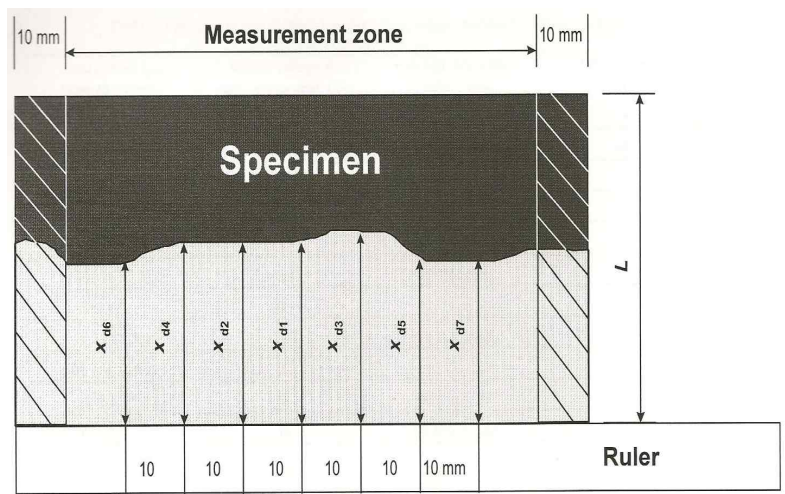

Figure 3. Measurement of Chloride Ion Migration

$$
\begin{aligned}
D=1.189 \times 10^{-11}\left(\frac{x_{d}-1.061 x_{d}^{0.589}}{t}\right) \cdots \cdots \ldots(\text { Exp. 1) } \\
\text { D }: \text { Chloride Diffusion Coefficient }\left(\mathrm{m}^{2} / \mathrm{sec}\right) \\
\mathrm{x}_{d}: \text { Depth of Penetration }(\mathrm{mm}) \\
\mathrm{t}: \text { hour }
\end{aligned}
$$

\section{Experiment results and considerations}

\subsection{Compressive strength}

\subsubsection{At 3 days}

Figure 4 shows the initial compressive strength of each specimen at 3 days. Regardless of mix proportion, the compressive strength of the specimens with BFS or with FA was lower than that of Plain. The more BFS or FA was mixed, the lower the compressive strength was at 3 days. It is believed that as BFS or FA was mixed more, the unit cement content became relatively lower, which might cause hydration reaction to be retarded, and an insufficient yield of calcium hydroxide failed to trigger pozzolanic reaction or hydration reaction.

However, in the specimen with SF and RHA, the compressive strength was 17\% 20\% higher than that of Plain. As indicated in the previous studies, the higher compressive strength was caused by pozzolanic reaction and the filling effect of particles.

In terms of the specimens, the compressive strength gradually increased up to $10 \%$ of mix proportion, but it decreased when the mix proportion was higher than 10\%. Compared to the specimens with SF, the initial compressive strength of the specimens was shown to be similar when there was the same mix proportion of SF or of RHA. Therefore, it is believed that cement with RHA can secure an initial compressive strength equal to cement with SF.

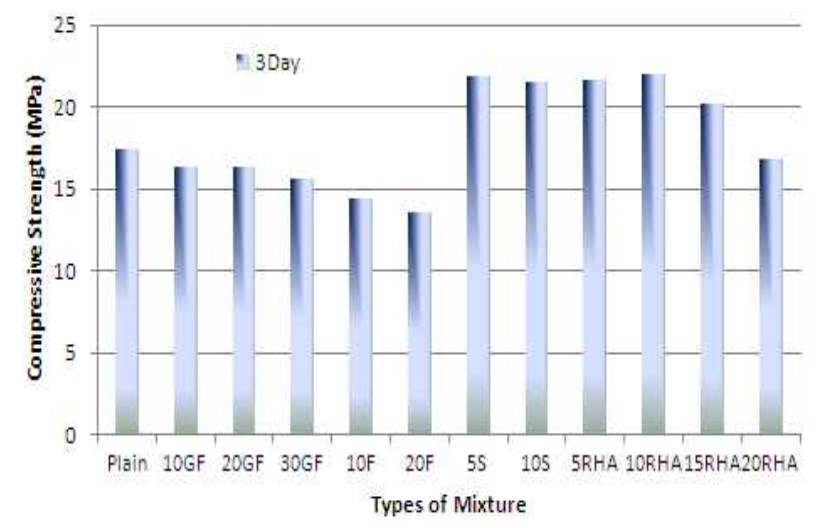

Figure 4. Compressive Strength at 3 Days 


\subsubsection{At 7 days}

Figure 5 shows the compressive strength of each specimen at 7 days. Except for the specimens with FA, the specimens with an admixture showed higher compressive strength overall compared to Plain.

The specimens with BFS were found to have different strength development at 3 days. The more BFS was added, the higher strength developed. In particular, when the mix proportion of BFS was set at $20 \%$ and $30 \%$, the compressive strength was measured as $27.14 \mathrm{MPa}$ and $27.5 \mathrm{MPa}$, respectively. It is believed that the hydration reaction of BFS particles was more highly activated with the passage of time, filling the inside of concrete more densely.

The specimens with FA showed similar strength development at 3 days. When the mix proportion of FA was set at $10 \%$ and $20 \%$, the compressive strength was measured at $21.40 \mathrm{MPa}$ and 20.63MPa, respectively, which was lower than $22.11 \mathrm{MPa}$ of Plain. The more FA was mixed, the lower the compressive strength, from which it can be interpreted that the pozzolanic reaction became retarded up to 7 days.

The specimens with SF were measured to have $30 \%$ higher compressive strength than Plain. The more SF was mixed, the higher the compressive strength became.

The specimens with RHA showed an increase in compressive strength up to $10 \%$ of mix proportion. However, the more RHA was mixed, the lower the compressive strength became. In particular, the compressive strength of specimens with RHA was higher than those with SF up to $10 \%$ of mix proportion. It is believed that the particles of RHA are much finer than SF, and the filling effect of RHA is better than that of SF.

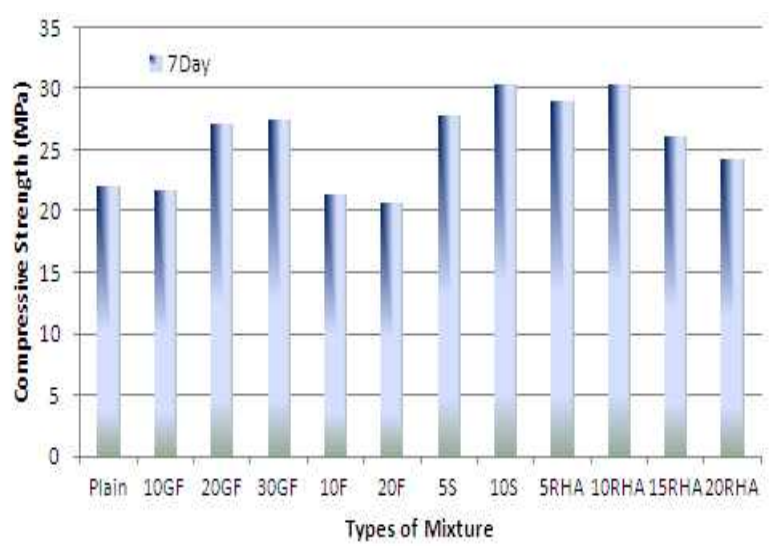

Figure 5. Compressive Strength at 7 Days

\subsubsection{At 14 days}

Figure 6 shows the compressive strength of each specimen at 14 days. The compressive strength of specimens with an admixture was higher overall than that of Plain.

The specimens with BFS developed a similar compressive strength to the result at 7 days. The more BFS was added, the higher the developed compressive strength.

The specimens mixed with FA showed slightly higher compressive strength than Plain due to the pozzolanic reaction. The more FA was mixed, the higher the developed compressive strength.

The specimens mixed with SF or RHA showed compressive strength similar to the result at 7 days. In particular, when the mix proportion of RHA was set at $10 \%$, the compressive strength was shown to be the highest.

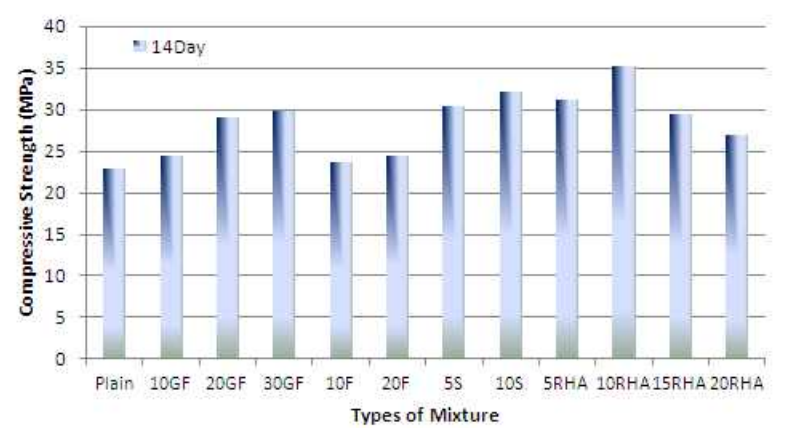

Figure 6. Compressive Strength at 14 Days 


\subsubsection{At 28 days}

Figure 7 illustrates the compressive strength of each specimen at 28 days. The specimens showed overall higher compressive strength compared to Plain, which was similar to the result at 14 days.

In particular, the specimens with $\mathrm{SF}$ or with RHA showed the highest compressive strength at 28 days. With longer-term curing, this tendency would become stronger. In comparison with the compressive strength at 14 days and 28 days, the concrete with $10 \%$ RHS is believed to be most advantageous to secure initial compressive strength and long-term strength.

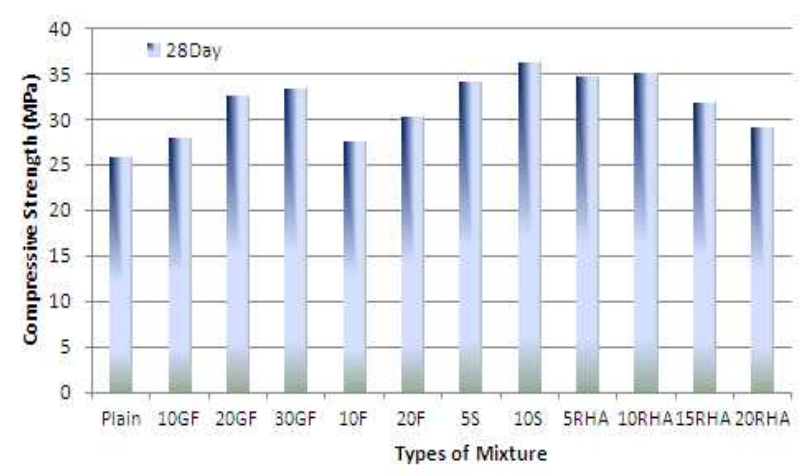

Figure 7. Compressive Strength at 28 Days

Table 7. Compressive Strength of Types of Mixture

\begin{tabular}{ccccc}
\hline Kind of & \multicolumn{4}{c}{ Compressive Strength(MPa) } \\
Mixture & 3Day & 7Day & 14Day & 28Day \\
\hline Plain & 17.42 & 22.11 & 22.96 & 25.77 \\
GF10 & 16.39 & 21.77 & 24.41 & 27.95 \\
GF20 & 16.28 & 27.14 & 28.98 & 32.61 \\
GF30 & 15.58 & 27.50 & 29.85 & 33.32 \\
FA10 & 14.45 & 21.40 & 23.74 & 27.58 \\
FA20 & 13.56 & 20.63 & 24.42 & 30.19 \\
SF5 & 21.92 & 27.80 & 30.34 & 34.18 \\
SF10 & 21.52 & 30.40 & 32.22 & 36.22 \\
RHA5 & 21.59 & 28.93 & 31.16 & 34.68 \\
RHA10 & 22.02 & 30.31 & 35.22 & 35.15 \\
RHA15 & 20.23 & 26.09 & 29.48 & 31.82 \\
RHA20 & 16.82 & 24.30 & 26.80 & 29.10 \\
\hline
\end{tabular}

\subsection{Facilitated neutralization test}

Figure 8 shows the depth of penetration by specimen at 56 days and 84 days. In the facilitated neutralization test, the greatest depth of penetration of Plain was measured as $7 \mathrm{~mm}$ and $9.8 \mathrm{~mm}$, respectively.

In terms of the specimens with BFS, the more BFS was mixed, the shorter the depth. As a possible cause, it was suggested that the BFS triggered a hydration reaction, causing the dense filling of the inside of the specimen with the passage of time, and strengthening the penetration resistance.

In terms of the specimens with FA, the more FA was mixed, the shorter the depth. But the rate of decrease was greater compared to the specimens with BFS. This was because when FA was added, the pozzolanic reaction became more activated with the passage of time, the concrete with FA was filled more densely, and the penetration resistance became strong compared to the specimens with BFS as a result.

In terms of the specimens with SF, the penetration resistance was shown to be low overall regardless of the mix proportion. In particular, when $10 \% \mathrm{SF}$ was mixed, the depth of $\mathrm{CO}_{2}$ penetration was measured as $4.9 \mathrm{~mm}$, which is the most excellent in terms of penetration resistance.

For the specimens with RHA, the depth of $\mathrm{CO}_{2}$ penetration was similar to that of the ones with SF up to $10 \%$, which is believed to be a very good penetration resistance. As mentioned earlier, when RHA is added, pozzolanic reaction became active and fine particles of each material filled the inside the concrete more densely, which may prevent $\mathrm{CO}_{2}$ in the air from going into the specimens.

However, when more than 15\% RHA is added, the penetration depth tended to increase, and if the mix proportion is higher than a certain level, it would reduce durability. 


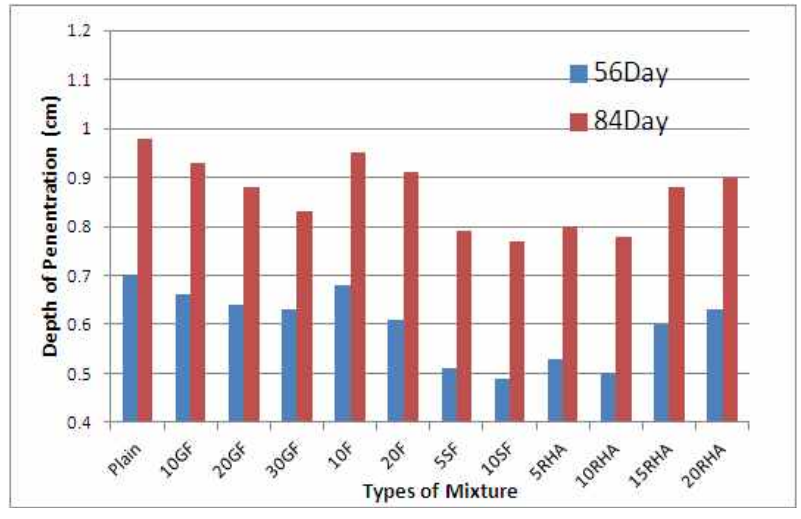

Figure 8. Compressive Strength at 28 Days

\subsection{Chloride diffusion coefficient}

Table 8 indicates the chloride diffusion coefficient of each specimen at 28 days or 56 days after the facilitated chloride diffusion tests. The chloride diffusion coefficient was also shown to be similar to the test results of facilitated neutralization tests. Plain showed a rather low chloride diffusion coefficient compared to other specimens.

With the passage of time, all the specimens tended to have a lower diffusion coefficient, which is believed to indicate that the hydration reaction was more active over time, and the inside of the specimens became denser, accordingly.

In terms of the chloride diffusion coefficient at 28 days and at 56 days, Plain was measured at $13.4 \times 10^{-12} \mathrm{~m}^{2} / \mathrm{sec}$ and $10.8 \times 10^{-12} \mathrm{~m}^{2} / \mathrm{sec}$, which was the greatest of all the specimens.

BFS and FA specimens showed a similar tendency to the neutralization penetration depth. The higher the mix proportion became, the lower the chloride diffusion coefficient. As mentioned earlier, it is believed that latent hydraulic property and pozzolanic reaction made the concrete more dense, which caused the chloride ions to be less penetrated. However, unlike the previous studies, the specimens with BFS showed slightly higher chloride diffusion coefficients than those with FA.
For this reason, further studies should be conducted.

The specimens with SF were shown to have a very low chloride diffusion coefficient, with no great differences according to mix proportion. With the passage of time, the chloride diffusion coefficient became lower, which means the penetration resistance was highest.

In terms of the specimens with RHA, the chloride diffusion coefficient was shown to be very low up to a mix proportion of $10 \%$, from which it can be interpreted that they would have an excellent chloride penetration resistance. And, when the mix proportion was set at $15 \%$ or higher, the chloride diffusion coefficient tended to increase, which was not high compared with other specimens. However, like the facilitated neutralization test results, when the mix proportion was set at higher than a certain level, the durability might be compromised.

Table 8. Chloride Ion Migration Coefficient of Types of Mixture

\begin{tabular}{|c|c|c|}
\hline \multirow{2}{*}{$\begin{array}{l}\text { Kind of } \\
\text { Mixture }\end{array}$} & \multicolumn{2}{|c|}{$\begin{array}{l}\text { Chloride lon Migration } \\
\text { Coefficient }\left(X 10^{-12} \mathrm{~m} / \mathrm{sec}\right)\end{array}$} \\
\hline & 28Day & 56Day \\
\hline Plain & 13.4 & 10.8 \\
\hline GF10 & 9.3 & 8.0 \\
\hline GF20 & 8.1 & 7.5 \\
\hline GF30 & 7.7 & 6.5 \\
\hline FA10 & 8.0 & 7.3 \\
\hline FA20 & 7.3 & 6.5 \\
\hline SF5 & 4.0 & 3.3 \\
\hline SF10 & 3.8 & 2.6 \\
\hline RHA5 & 4.1 & 3.5 \\
\hline $\mathrm{RHA} 10$ & 3.7 & 2.9 \\
\hline $\mathrm{RHA} 15$ & 5.0 & 4.4 \\
\hline RHA20 & 8.0 & 6.5 \\
\hline
\end{tabular}

\section{Conclusion}

In this study, RHA was mixed as an admixture, and the compressive strength and neutralization 
penetration depth and chloride diffusion coefficient of the specimens with RHA were compared with those of the specimens with other admixtures. The following are the findings of this study.

1) Through the initial strength measurement, when RHA was mixed, high compressive strength developed overall, which showed a similar result when SF was mixed. When the mix proportion was set at $15 \%$ or higher, the compressive strength was retarded.

2) In terms of long-term strength, the specimens with RHA showed higher overall compressive strength, but when the mix proportion was set at $15 \%$ or higher, the compressive strength was retarded, and the appropriate mix proportion was shown to be $10 \%$.

3) Through the facilitated neutralization test, with the passage of time the neutralization penetration depth increased; however, the specimens with RHA were shown as significantly lower compared with the specimens with other admixture. In other words, when RHA was used as an admixture, the neutralization resistance was very good.

4) Through the chloride penetration test, the chloride diffusion coefficients tended to decrease. When RHA was added, the chloride diffusion coefficients of the specimens with RHA were very low, showing excellent chloride diffusion resistance. Therefore, when RHA was used as an admixture, it was very good in terms of compressive strength and penetration resistance. When the mix proportion was set at a certain level or higher, they tended to decrease, and thus the optimal mix proportion was believed to be up to $10 \%$. For the wide use of an admixture of RHA, efforts should be made to collect data on the site applicability by measuring the durability of large-sized specimens.

\section{References}

1. Ryu DW, Kim WJ, Yang WH, Park DC. An experimental study on the carbonation and drying shrinkage of concrete using high volumes of ground granulated blast-furnace slag. Journal of Korea Institute of Building Construction. 2012 Aug;12(4):393-8.

2. Al-Amoudi OSB, Maslehuddin M. The effect of chloride and sulfate ion on reinforcement corrosion. Cement and Concrete Research. 1993 Jan;23(1):139-46.

3. ACI Committee 222. Protection of Metal in Concrete Against Corrosion. Oakland County: Farmington Hill; 2012. p. 1-41.

4. Kim YS, Lee DW. A study on the magnesium sulfate attack resistance of ternary concrete containing metakaolin. Journal of the Architectural Institute of Korea. 2012 Nov;28(11):117-8.

5. Shin SY, Effects of firing temperatures and average particle size of rice husk ash on compressive strength properties of concrete [dissertation]. [Pu-San (Korea)]: Pusan National University; 2008. p. 1-55.

6. Luxan MP, Madruga F, Saavedra J. Rapid evaluation pozzolanic activity of natural products by conductivity measurement. Cement and Concrete Research. 1989 Jan;19(1):63-8.

7. Jung YH, Lee JY, Kim YS. Effects of rice husk ash on the additional evaporable water and products by alkali-silica reaction of the mortar bars. Journal of the Architectural Institute of Korea. 2005 May;21(9):105-8.

8. Mehta PK. Rice husk ash - a unique supplementary cement material. Advances in Concrete Technology. 1992 May;34(1):125-30.

9. Bae SH. An Experimental Study on the Characteristics of Concrete Containing Rice Husk Ash. Proceeding of 1996 Symposium on Korea Concrete Institute; 1996 Nov: Seoul. Seoul: Korea Concrete Institute; 1996. p. 70-6.

10. Kim YS, Lee DW. A study on the steel corrosion properties of the concrete containing wasted tile powder. Journal of the Architectural Institute of Korea. 2010 Jan;26(1):105-8. 